\title{
Effect of Intraduodenal Lipid on Parabrachial Gustatory Coding in Awake Rats
}

\author{
Andras Hajnal, Kaoru Takenouchi, and Ralph Norgren \\ Department of Behavioral Science, College of Medicine, The Pennsylvania State University, Hershey, Pennsylvania 17033
}

Intestinal fat differentially suppresses sham feeding of liquid diets and preferred gustatory stimuli. Although the behavioral effect is robust, no electrophysiological evidence exists to account for its neural basis. Therefore, we investigated the effect of intestinal fat on gustatory coding in the pontine parabrachial nuclei (PBN) by recording from single neurons in awake rats before, during, and after intraduodenal infusions of lipid (Intralipid; $10 \mathrm{ml}, 5 \mathrm{kcal})$. Intraduodenal lipid did not alter the response profiles of PBN taste neurons. It did, however, produce an overall decrease in response magnitude $(-16.25 \%$; $n=43)$, with the largest reduction to sucrose $(-30 \% ; n=43)$. The most pronounced suppression occurred in sucrose-best neurons in response to sucrose $(-55 \% ; n=19)$, and this effect was largest for the sucrose-specific cells $(-77 \% ; n=3)$. After lipid infusions, nonspecific neurons in both the sucrose-best and $\mathrm{NaCl}$-best categories also responded less to their best stimulus (sucrose, $-46 \% ; n=16 ; \mathrm{NaCl},-35 \% ; n=13$ ). In contrast, no significant changes were found in $\mathrm{NaCl}$-specific cells in response to $\mathrm{NaCl}$. All effects appeared with short latency ( $\sim 5 \mathrm{~min}$ ) and were reversible within the time frame of a meal. In controls, duodenal infusions of saline did not cause any changes in taste responsiveness. These results suggest that intestinal fat has specific effects on taste coding in the PBN that may contribute to the intake suppression of palatable food observed in behavioral studies. The similar, short latency of both the behavioral and neural effects supports the hypothesis of a preabsorptive site of action.

Key words: gustatory coding; sucrose; sodium; lipid; duodenum; postprandial satiety; single-unit recording; pontine parabrachial nucleus; rats
Food intake is controlled by both sensory and metabolic mechanisms. Within the time frame of a meal, however, an ability to select essential nutrients cannot be based on the metabolic consequences of food currently being consumed. Nevertheless, it could be attributable to the individual associative history of a previous food with the orosensory characteristics of that food. Thus, in the short-term regulation of feeding (meal size, postprandial satiety), the sensory components of food play a dominant role ("direct control of meal size") (Smith, 1996). The sensory control of meal size is the result of integration of orosensory feedback from gustatory, olfactory, and somatosensory receptors, and postingestive feedback from the stomach and small intestine. Sham-feeding preparations are used to isolate the orosensory from the postingestive effects of nutrients.

Using such preparations, numerous studies demonstrate that fat infusions into the duodenum decrease food intake during real or sham feeding in different species (Liebling et al., 1975; Novin et al., 1979; Reidelberger et al., 1983; Gregory and Rayner, 1987; Welch et al., 1988; Greenberg et al., 1990; Foster et al., 1996, 1998). The inhibitory effect of intraduodenal fats on sham feeding is a function of concentration (Reidelberger et al., 1983; Green-

Received April 6, 1999; revised June 1, 1999; accepted June 7, 1999.

This research was supported by National Institutes of Health Grants DC 00240 and MH 43787. R.N. is a recipient of National Institute of Mental Health Research Scientist Award MH 00653. A.H. is supported partially by the Hungarian Academy of Sciences (MTA) at the Neurophysiology Research Group of MTA at the Department of Physiology, University Medical School, Pecs, Hungary. We thank Drs. B. Li and H. Nishijo for methodological advice, Dr. P. S. Grigson for comments on an earlier draft of this manuscript, and K. Smith for histology.

Correspondence should be addressed to Dr. Andras Hajnal, Department of Behavioral Science, College of Medicine, The Pennsylvania State University, Hershey, PA 17033.

Dr. Takenouchi's present address: Department of Neuropsychiatry, Kagoshima University, Kagoshima 890-8520, Japan.

Copyright (C) 1999 Society for Neuroscience 0270-6474/99/197182-09\$05.00/0 berg et al., 1990; Foster et al., 1996). Furthermore, recent studies in our laboratory show that intestinal fat (Intralipid) differentially suppresses sham drinking of gustatory stimuli (Foster et al., 1996, 1998). Intake suppression caused by intestinal fat was the most pronounced for the most preferred diets (polycose and sucrose) (Foster et al., 1996). The short latency of the effects implies a preabsorptive site of action.

Although the results of the behavioral experiments provide strong evidence that intestinal lipid has differential effects on intake suppression of nutrients, the underlying neuronal mechanisms are unknown. In the present experiment, we investigated the effect of intraduodenal infusions of lipid on gustatory coding in the pontine parabrachial nuclei $(\mathrm{PBN})$, the second central gustatory relay, by recording from single neurons in rats. In rodents, the PBN apparently contain an obligate synapse in the central gustatory system, and they have connections with the neural areas thought to be important in processing gustatory afferent activity (Norgren, 1974, 1976, 1990, 1995). Studies from this laboratory provided further data about the parabrachial gustatory coding in awake rats (Nishijo and Norgren, 1990, 1991, 1997). To make direct comparisons between the neurophysiological and behavioral data, the present experiment also was performed in awake, behaving rats.

Results from a subset of these data have appeared as an abstract (Hajnal et al., 1998).

\section{MATERIALS AND METHODS}

Subjects and first surgery. All experimental protocols were approved by the Local Review Committee and followed National Institutes of Health guidelines. Twelve male Sprague Dawley rats (340-440 gm; Charles River, Wilmington, MA) were housed individually on a $12 \mathrm{hr}$ light/dark schedule (lights on at 7:00 A.M.). The rats were kept on a standard laboratory diet [Rodent Diet (W) 8604; Harlan Teklab, Madison, Wisconsin], which consists of $4.4 \%$ fat ( $\sim 10 \%$ of total calories). 
Except for the duodenal surgery and infusions, the procedures used in the present study were identical to those of our previously published experiments (Nishijo and Norgren, 1990, 1997). Before surgery, the rats were acclimated by handling and accustomed to being placed into a small, plastic restraining cage (Clear Acrylic; Fisher Scientific, Houston, TX) for increasing periods (up to $2 \mathrm{hr}$ ) while on a water deprivation regimen (see Materials and Methods, Training). Surgical procedures were performed under aseptic conditions in two stages. The rats were food deprived overnight, given atropine the next morning ( $0.1 \mathrm{mg} / \mathrm{rat}$, i.p.), and then anesthetized (pentobarbital sodium, Nembutal; $50 \mathrm{mg} / \mathrm{kg}$, i.p.). In the first stage, a dental acrylic headpiece was mounted onto the skull, and catheters were implanted into the oral cavity. After 8-10 d recovery and a subsequent $\sim 1$ month training period, the rats were reanesthetized and implanted with a duodenal catheter, and gustatory responses were localized in the PBN.

Briefly, in the first surgery, after being anesthetized, the rat was mounted in a stereotaxic apparatus using blunt ear bars, with the skull leveled between $\beta$ and $\lambda$. The cranium was exposed, and seven sterile stainless steel screws (1-72 × 1/8 inch; Small Parts Inc., Miami Lakes, FL) were threaded into holes in the skull to serve as anchors for cranioplastic acrylic. Stainless steel wire was soldered onto two screws to serve as a ground. The acrylic was built up on the skull and molded around the conical ends of two sets of stainless steel rods that were attached rigidly to the ear bars. During subsequent chronic recording sessions, these rods were reattached to the ear bars more medially and fitted back into the acrylic impressions, thus painlessly fixing the rat's head in the stereotaxic plane. Intraoral cannulas (PE-100; Clay Adams, Parsippany, NJ) were implanted bilaterally, just anterior to the first maxillary molar, brought out subcutaneously, and embedded in the cranioplastic acrylic (Phillips and Norgren, 1970).

Training. After recovery $(8-10 \mathrm{~d})$ from surgery, the rats were reacclimated to the plastic restraining cage, placed on a $22 \mathrm{hr}$ water deprivation regimen, and trained to take $0.3 \mathrm{M}$ sucrose and water from a spout while in the restrainer (1-2 hr daily, for $\sim 1$ week). After the rats learned to take their fluids while restrained, they were put in the stereotaxic instrument with their head fixed for gradually increasing periods. When they would remain calm in the stereotaxic frame for $3 \mathrm{hr}$, sucrose was replaced gradually with distilled water, first via the spout, and then via the intraoral cannulas. During the next stage of training (7-10 d), the rats received occasional infusions of the tastes, preceded and followed with water, to familiarize them with the solutions. At this stage, intraduodenal lipid inf usions also were introduced gradually $(3,5$, and $10 \mathrm{ml}$ on the first, second, and third days, respectively). Some of the oral stimulus and water trials occurred during and after the lipid infusions, again to make certain that when recording began the experience would not be novel. These procedures produced no evidence of learned taste aversion (see Discussion).

The method of intraoral taste stimulation via oral cannulas was described previously in detail (Grill and Norgren 1978a,b). Briefly, water and tastants were delivered from a handheld, $1.0 \mathrm{ml}$ hypodermic syringe through a length of PE-10 tubing (Clay Adams) constructed so that its tip protruded 1-2 $\mathrm{mm}$ beyond the oral end of the cannula. This arrangement ensured that fluid was delivered directly into the oral cavity and did not reflux up the lumen of the cannula.

Throughout training and recording, if the rats failed to ingest at least $15 \mathrm{ml}$ of water while in the restrainer, they received the remainder in their home cages. The rats were weighed weekly to ensure that they were not losing weight.

Localization of taste area and implantation of duodenal catheter. After this training ( $\sim 1$ month), the rats were reanaesthetized and mounted in the stereotaxic instrument. To reduce the consequences of repeated anesthesia and surgical traumas, this procedure was performed at the same time as the duodenal catheter implantation. Just caudal to the interparietal suture, a $3 \times 5 \mathrm{~mm}$ oval area of the acrylic and underlying bone was drilled away, the exposed dura was excised, and the PBN gustatory area was located electrophysiologically using an electrode tilted $20^{\circ}$ off perpendicular (tip anterior) to avoid damage to the transverse sinus. A stainless steel wire ( $178 \mu \mathrm{m}$ in diameter), insulated except at the cross section of the tip, was implanted near the midline in the dorsal medulla to serve as an indifferent electrode. After these procedures and, subsequently, between chronic recording sessions, the exposed brain was treated with an antibiotic-steroid ointment (Neo-Predef; Pharmacia \& Upjohn Co., Clayton, NC). The hole was covered with Teflon sheet and sealed with two-component epoxy glue, and antibiotic was administered for $3 \mathrm{~d}$ (Gentamicin $5 \mathrm{mg}$, i.m.).
To implant the duodenal catheter, we used the method of Walls et al. (1995), as modified by Dr. G. J. Schwartz (The Johns Hopkins University School of Medicine, Baltimore, MD, personal communication). After a 5 $\mathrm{cm}$ midline incision had been made in the abdomen exposing the liver and small intestines, the duodenum was perforated $1 \mathrm{~cm}$ aboral from the pyloric sphincter with a 22 gauge needle. SILASTIC tubing [0.012 inner diameter (i.d.) $\times 0.025$ outer diameter (o.d.), $20 \mathrm{~cm}$ ] was inserted through this perforation up to a $1 \mathrm{~cm}^{2}$ piece of Marlex mesh that had been attached to the tubing with silicone cement $2 \mathrm{~cm}$ from the end. This mesh was sewn onto the duodenum, immobilizing the $2 \mathrm{~cm}$ segment of tubing within. The free end of the tubing was drawn through a small puncture on the left abdominal wall and then threaded subdermally to the neck where a $2.5 \mathrm{~cm}$ interscapular midline incision had been made previously. A piece of $2 \times 3 \mathrm{~cm}$ Marlex mesh sealed together with a $4 \mathrm{~cm}$ length SILASTIC tubing $(0.025$ o.d. $\times 0.047$ i.d.) served as a subcutaneous base for the outer end of the duodenal catheter. Rats were treated with both topical (Erythromycin 0.5\%; Bausch \& Lomb, Rochester, NY) and systemic antibiotics (Gentamicin, $5 \mathrm{mg}$ i.m.; Fujisawa USA, Deerfield, IL) for $3 \mathrm{~d}$. The catheter was flushed with $1 \mathrm{cc}$ of sterile saline before and after training and recording sessions.

Electrophysiological recording and sapid stimuli. After an animal learned to remain quiet for up to $2 \mathrm{hr}$ while it had an intraduodenal lipid inf usion and ingested 5-10 $\mathrm{ml}$ of fluid via an intraoral catheter, recording sessions began. The Teflon sheet and ointment were removed, and a glass-insulated tungsten microelectrode $(Z=1.5-3.5 \mathrm{M} \Omega$ at $1 \mathrm{kHz})$ was advanced through the cerebellum into the PBN. Extracellular neural activity was monitored on an oscilloscope and recorded on magnetic tape. After isolating a single unit, a trial began with $50 \mu \mathrm{l}$ of distilled water applied via the ipsilateral intraoral cannula and then a similar amount of sapid stimulus, followed by at least one water rinse of the same volume, all at room temperature $\left(23-25^{\circ} \mathrm{C}\right)$. The minimum interval between water and stimulus application was $15 \mathrm{sec}$ and between one taste stimulus and the next was $45 \mathrm{sec}$. The lipid infusion began after this initial sequence. After the onset of the gut infusion, the taste stimuli were tested every $5 \mathrm{~min}$, for as long as the cell remained isolated, in the following order (in $\mathrm{M}$ ): $0.1 \mathrm{NaCl}, 0.1$ sucrose, 0.01 citric acid, and $10^{-4}$ quinine- $\mathrm{HCl}$. Electrode penetrations into gustatory responsive areas were restricted to two per day, and at least $2 \mathrm{~d}$ separated each recording session.

Duodenal infusions. During daily training sessions, rats received a 10 $\mathrm{ml}$ inf usion of a fat emulsion (Intralipid 20\% diluted to 5\% soybean oil, $0.56 \%$ glycerin, $0.3 \%$ phospholipids, and $0.5 \mathrm{kcal} / \mathrm{ml}$; Pharmacia \& Upjohn Co.) or the same amount of sterile physiological saline at a rate of $1 \mathrm{ml} / \mathrm{min}$, both at room temperature $\left(23-25^{\circ} \mathrm{C}\right)$. The infusions began 15-20 min after the rats were placed into the stereotaxic instrument and were followed by an additional 60-90 min of restraint, during which more fluid was presented. Subsequently, in the home cage, they were allowed to drink the remainder of their $15 \mathrm{ml}$ of water. Approximately $15 \mathrm{gm}$ of powdered lab chow was presented at 6:00 P.M. This food was almost always ingested overnight. If not, what little remained was removed at least $3 \mathrm{hr}$ before the training or recording sessions started. This schedule assured a constant body weight while they were receiving $10 \mathrm{cc}$ Intralipid infusions. This amount of lipid infused in combination with the food restriction did not result in a substantial increase in the portion of the fat in the daily diet (e.g., $<20 \%$ calories from fat). Therefore, this schedule cannot be considered to be a chronic high-fat diet (Warwick and Schiffman, 1992; Warwick, 1996).

Data analysis. The single-unit activity was converted on-line to standardized pulses with a two-level voltage discriminator. These were accumulated in peristimulus histograms with $500 \mathrm{msec}$ bins using a personal computer. The signal-to-noise ratio of the single unit and the discriminator settings were monitored continuously using a storage oscilloscope. All data were archived on magnetic tape. In some cases, records were analyzed off-line, using an analog-to-digital converter and spike analyzing system (CED 1041, Spike 2 program, Cambridge Electronic Design Ltd., Cambridge, UK). Responses were calculated for $5 \mathrm{sec}$ from the onset of the peristimulus water or the taste infusion. For water, the mean spontaneous rate was subtracted from the raw water response, and for taste, the mean water response was substracted from the raw taste response. These corrected data were used in all statistical analyses. A response was considered significant if it deviated $\pm 2.5 \mathrm{SD}$ from the mean of the peristimulus water trials. Statistical analysis consisted of parametric and nonparametric ANOVA [single-factor ANOVA, MicroSoft Excel '97 (MicroSoft, Seattle, WA); two-way ANOVA, Kruskall-Wallis and 


\begin{tabular}{|c|c|c|c|c|c|}
\hline \multicolumn{2}{|l|}{ Total $(n=59)$} & \multicolumn{2}{|c|}{ Lipid infusion $(n=43)$} & \multicolumn{2}{|c|}{ Saline infusion $(n=16)$} \\
\hline Best-stimulus & Second-best & Best-stimulus & Second-best & Best-stimulus & Second-best \\
\hline NaCl-best 27 & $\begin{array}{l}\text { Ns } 9 \\
N>\text { S } 9 \\
N>C 9\end{array}$ & NaCl-best 18 & $\begin{array}{l}\text { Ns } 5 \\
N>\text { S } 4 \\
N>C 9\end{array}$ & NaCl-best 9 & $\begin{array}{l}\text { Ns } 4 \\
N>\text { S } 5\end{array}$ \\
\hline Sucrose-best 24 & $\begin{array}{l}\text { Ss } 5 \\
S>\text { N } 11 \\
S>\text { C } 6 \\
S>\text { Q } 2\end{array}$ & Sucrose-best 19 & $\begin{array}{l}\text { Ss } 3 \\
S>N 9 \\
S>C 5 \\
S>\text { Q } 2\end{array}$ & Sucrose-best 5 & $\begin{array}{l}\text { Ss } 2 \\
S>\text { N } 2 \\
S>C 1\end{array}$ \\
\hline Citric acid-best 5 & $\begin{array}{l}\mathrm{C}>\mathrm{N} 1 \\
\mathrm{C}>\mathrm{S} 3 \\
\mathrm{C}>\mathrm{Q} 1\end{array}$ & Citric acid-best 4 & $\begin{array}{l}\mathrm{C}>\mathrm{S} 3 \\
\mathrm{C}>\mathrm{Q} 1\end{array}$ & Citric acid-best 1 & $\mathrm{C}>\mathrm{N} 1$ \\
\hline QHC1-best 3 & $\begin{array}{l}\mathrm{Q}>\mathrm{N} 1 \\
\mathrm{Q}>\mathrm{S} 2\end{array}$ & QHC1-best 2 & $\mathrm{Q}>\mathrm{S} 2$ & QHC1-best 1 & $\mathrm{Q}>\mathrm{N} 1$ \\
\hline
\end{tabular}

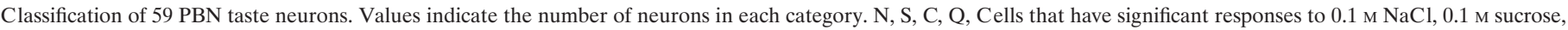

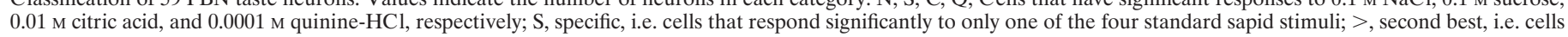
that responded significantly to at least two of the sapid stimuli. The stimulus after the $>$ sign produced a smaller but still significant response.

Friedman ANOVA, Statistica 5.1 (StatSoft Inc., Tulsa, OK)] followed by independent or paired $t$-tests where appropriate for comparisons of neural responses and either $\chi^{2}$ or Fisher's exact tests for comparisons between neural categories (Statistica 5.1). The Pearson's product-moment correlation coefficients for all possible pairs of responses were calculated and used to conduct cluster analysis (average linkage methods, Pearson's $r$, Statistica 5.1). Breadth of responsiveness was calculated for entropy based on both the absolute values and the excitatory components of the activity generated by each of the four tastants (Smith and Travers, 1979). The entropy $(H)$ measure of each neuron was given by the formula

$$
H=-1.661 \sum_{i=1}^{4} p_{i}\left(\log p_{i}\right),
$$

where $p_{i}$ is the proportional response to each of the four tastes. The $p_{i}$ for each cell is derived by converting the response profile for that cell to a proportional profile that maintains the relative differences among the four responses.

Histology. After the recording sessions, the animals were reanaesthetized, and small electrolytic lesions $(10 \mu \mathrm{A}$ for $5 \mathrm{sec})$ were made at the rostral, caudal, lateral, and medial margins of the gustatory responsive area in the pons. Subsequently, $10 \mathrm{ml}$ of saline colored with food dye was infused into the duodenum, and the abdomen was exposed to check for possible reflux of fluid into the stomach. Finally, the rats were given a further lethal dose of Nembutal $(100 \mathrm{mg} / \mathrm{kg}$, i.p. $)$ and perfused intracardially with $0.9 \%$ saline and $10 \%$ formalin. The brain was removed and cut coronally in $50 \mu \mathrm{m}$ sections, and alternate sections were stained with the cresyl Lecht violet and Weil methods.

\section{RESULTS}

\section{Histology}

A total of 458 penetrations was made into the pons in 12 rats; in eight of these 12 , both the left and right sides were explored. Single-unit or multiunit electrophysiological responses to sapid stimuli occurred during 275 of these penetrations, and testing of single neurons with the four standard taste stimuli was completed during 174. Based on the stereotaxic coordinates of the penetrations and the marking lesions, the taste-responsive neurons were located in the caudomedial quadrant of the PBN extending from near the dorsal surface of the pons through the brachium conjunctivum and into the compact layer of cells between the brachium conjunctivum and the mesencephalic trigeminal nucleus. This approximate location is consistent with our previous samples from chronic studies (Nishijo and Norgren, 1990, 1991, 1997) and with acute experiments in which localization was an objective (Norgren and Pfaffmann, 1975). Since the penetrations were made over the course of 1 month or more, and assuming an accuracy of at best $100 \mu \mathrm{m}$ for such measurement in chronic studies, more precise localization of individual recording sites is impractical.

\section{Basic characteristics of taste neurons before and after lipid infusions}

A total of 174 taste-responsive single PBN neurons was isolated and tested with the four standard taste stimuli. Of these, 63 were isolated before, during (10 $\mathrm{min})$, and for a minimum of $25 \mathrm{~min}$ after the intraduodenal infusions. Four of these responded significantly only to water, or with an excitatory response to water and inhibitory responses to one or two sapid chemicals. Of the remaining 59 cells, 43 were tested in lipid-infusion sessions and 16 in saline-infusion control sessions. The control neurons were recorded from both rats that were previously trained with daily inf usions of lipid and rats trained with saline ( $n=9 ; n=7$, respectively). Before the infusions, no significant differences in response properties occurred between these two subpopulations or between the lipid and saline samples for any parameters. For the entire sample of 59 cells, the average length of recording was $65 \mathrm{~min}$ (range of 40-110 min), including the test periods before and during infusions. The mean spontaneous firing rate of 59 taste cells was $6.1 \pm 0.8(\mathrm{SEM})$ spikes/sec (range of $0.3-18$ spikes/sec).

Based on the largest response to the standard stimuli, the neurons were classified as follows: $27 \mathrm{NaCl}$-best (Nb, 45.8\%), 24 sucrose-best $(\mathrm{Sb}, 40.6 \%), 5$ citric acid-best $(\mathrm{Cb}, 8.5 \%)$, and 3 QHCl-best (Qb, 5.1\%). Of these 59 neurons, 14 (23.7\%) were "specific"; that is, they responded significantly only to one of the taste stimuli [NaCl-specific (Ns), 9; 33.3\%; sucrose-specific (Ss), $5 ; 20.8 \%$ ]. For further classification of the cells, see Table 1.

Intraduodenal infusions of either lipid or saline had no effect on the distribution of cells across the best-stimulus categories. Within best-stimulus categories, the distribution of specific responses after lipid infusion was identical to that found before the treatment. 


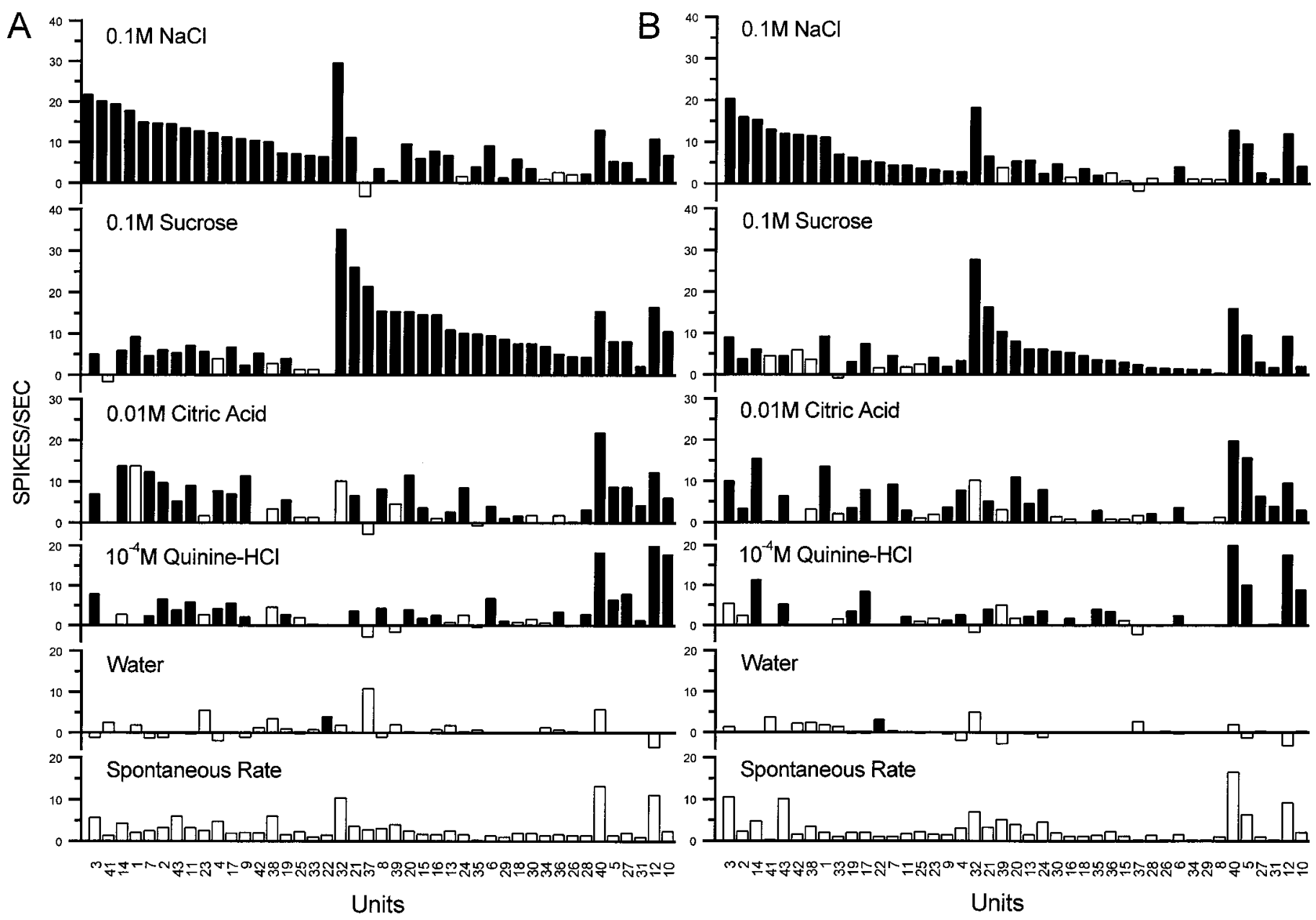

Figure 1. Spontaneous firing rates and response profiles of $43 \mathrm{PBN}$ taste neurons to the four standard taste stimuli and to water before $(A ; n=43)$ and after $(B ; n=43)$ intraduodenal infusions of lipid (Intralipid $10 \mathrm{ml}, 0.5 \mathrm{kcal} / \mathrm{ml})$. All cells were tested with all stimuli. Neurons are grouped into best-stimulus categories and arranged within those categories in decreasing order of response magnitude to the best stimulus. There are 18 NaCl-best, 19 sucrose-best, 4 citric acid-best, and 2 QHCl-best neurons. Taste responses were adjusted for average water responses; the response to water was adjusted for spontaneous rates. Spontaneous rates are shown at the bottom with unit numbers. Filled bars, Significant responses (for criterion, see Materials and Methods). Excitatory responses are up; inhibitory responses are down. None of the inhibitory taste responses reached the criterion for significance.

\section{Response profile changes in response to intraduodenal lipid}

The individual response profiles of all 59 neurons before and after lipid infusions are displayed in Figure 1. The spontaneous activity and response profile of each neuron recorded before (Fig. $1 A$ ) and after (Fig. $1 B$ ) lipid inf usions are arranged in descending order of response magnitude, beginning with the NaCl-best cells on the left, followed by the sucrose-best, then the citric acid-best, and then the QHCl-best neurons. The number of cells in each best-stimulus category appears in Table 1. Filled bars represent significant responses. In all figures and throughout the text, if is it not specified otherwise, the "after lipid" data were generated in the period immediately after the offset of lipid infusions (i.e., 10 min after the onset of infusions).

The mean effect of lipid on the spontaneous rate and water and taste responses across the best stimulus categories are depicted in Figure 2. After lipid infusions, no significant differences were found in spontaneous rate (ANOVA; $F_{(1,84)}=0.009 ; p=0.922$; $\chi^{2}=0.4195 ; \mathrm{df}=1 ; p=0.512$ ) or in water responses (ANOVA; $F_{(1,84)}=1.27 ; p=0.262 ; \chi^{2}=2.279 ; \mathrm{df}=1 ; p=0.131$ ) compared with the basal condition. In contrast, lipid did have an effect on overall taste responses of the PBN (Fig. 2). The magnitude of total taste responsiveness decreased $16.25 \%$ (two-way ANCOVA; $\left.F_{(3,252)}=5.47 ; p<0.01\right)$. Across the four sapid stimuli, the responses to sucrose decreased $30 \%$ (ANOVA; $F_{(1,84)}=$ $7.065 ; p<0.01 ; n=43)$, to $\mathrm{NaCl} 19 \%$ (ANOVA; $F_{(1,84)}=4.282$; $p<0.05 ; n=43)$, and $8 \%$ for both citric acid and QHCl $\left(F_{(1,84)}\right.$ $=0.439 ; p>0.5 ; n=43 ; F_{(1,84)}=0.594 ; p>0.4 ; n=43$, respectively).

The magnitude of the effect differed across best-stimulus categories. The most pronounced suppression $(-55 \%)$ occurred in sucrose-best neurons responding to sucrose (ANOVA; $F_{(1,36)}=$ 8.817; $p<0.01 ; n=19$ ), followed by sodium-best neurons responding to $\mathrm{NaCl}\left(-32 \%\right.$; ANOVA; $F_{(1,34)}=6.277 ; p<0.05$; $n=18$ ). Although few in number, neither the citric acid-best $(n=$ 4) nor the QHCl-best $(n=2)$ neurons (Fig. 2, $C b, Q b)$ exhibited 

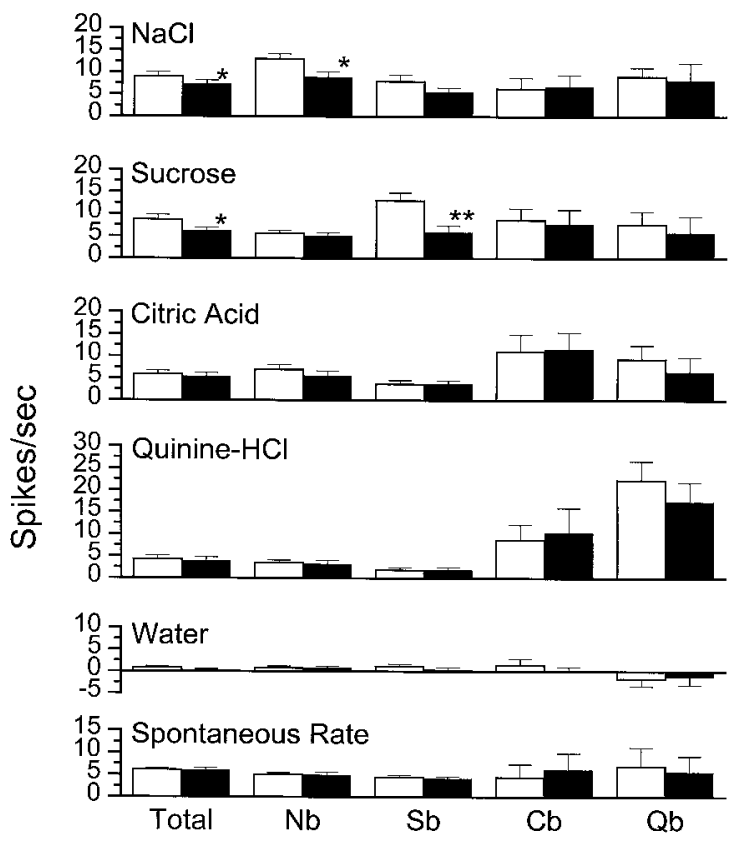

Figure 2. Comparison of average responses and spontaneous rates before and after intraduodenal infusion of lipid across best-stimulus categories. $\mathrm{Nb}, \mathrm{Sb}, \mathrm{Cb}, \mathrm{Qb}, \mathrm{NaCl}$-best, sucrose-best, citric acid-best, and QHCl-best, respectively. Open bars, Before lipid; filled bars, after lipid. $* p<0.05 ; * * p<0.01$.

any significant change in response to any stimulus after intestinal lipid infusions.

Further analysis of the subgroups revealed important differences between the sucrose-best and NaCl-best neurons (Fig. 3). After lipid infusions, the responses of sucrose-specific cells to sucrose (Fig. 3Aa) dropped to one-quarter of the basal values $\left(-77 \% ; F_{(1,4)}=76.31 ; p<0.001 ; n=3\right)$, whereas the more broadly tuned sucrose-best sample (Fig. $3 A a, S x$ ) decreased by one-half $\left(-46 \% ; F_{(1,30)}=5.78 ; p<0.05 ; n=16\right)$. The difference in the degree of response suppression in the two subcategories of sucrose-best units was statistically significant (Sx vs Ss, $\chi^{2}=7.26$; $p<0.01)$.

In contrast to the sucrose-specific cells, lipid failed to change the responses of $\mathrm{NaCl}$-specific units to an $\mathrm{NaCl}$ stimulus (Ns, $F_{(1,8)}=0.412 ; p=0.538 ; n=5$ ) (Fig. $\left.3 B b\right)$, but other NaCl-best neurons did drop 35\% $\left(\mathrm{Nx}, F_{(1,24)}=6.588 ; p<0.05 ; n=13\right)$. When NaCl-best cells were tested with sucrose (Fig. $3 A b$ ) and sucrose-best units with $\mathrm{NaCl}$ (Fig. $3 B a$ ), duodenal lipid infusions had no influence on the responses. This even held when sucrose was the second most effective stimulus for an NaCl-best cell (Fig. $3 A b, N S$ ) or $\mathrm{NaCl}$ was second for sucrose-best cells (Fig. $3 B a$, $S N)$. When saline was substituted for lipid, the duodenal infusions had no effect on any category of PBN gustatory neurons $(n=16)$ (Fig. 3C,D). In other words, lipid infusions reduced the sensory responses of parabrachial gustatory neurons only when sucrose or $\mathrm{NaCl}$ was the stimulus and then only when the cells responded best to sucrose or $\mathrm{NaCl}$, respectively.

\section{Breadth of responsiveness}

In the present study, 23.7\% (14 of 59) of the taste neurons were specific to one of four sapid stimuli. Under basal conditions, the mean entropy measures for the absolute values and excitatory components of the gustatory responses were 0.80 and 0.77 , respectively. For the specific cells, these mean entropy values were
0.52 and 0.44 . The lipid inf usion resulted in significant changes in the breadth of responsiveness only for the sucrose-specific cells. Their entropy values increased from 0.32 to $0.64\left(F_{(1,4)}=20.72\right.$; $p<0.01 ; n=3$ ) because, after the lipid inf usions, the response to sucrose decreased substantially, but the responses to the other sapid stimuli did not. Nevertheless, the increased entropy value did not reflect a change in the best-stimulus category of sucroseresponsive cells, although, based on our criteria, the gustatory responses became nonsignificant after the lipid infusions.

\section{Time course of the duodenal infusion effect}

With the exception of the $\mathrm{NaCl}$-specific neurons, all cells in the $\mathrm{NaCl}$-best and sucrose-best categories showed a significant decrease in response magnitude to their best stimulus. The reduction in taste responsiveness appeared with a short latency $(\sim 5$ min), and reached maximum in the 10 min after the end of the lipid infusions. The mean changes in response magnitude differed across best-stimulus categories in response to their best-taste $(\mathrm{Nb}$ to $\mathrm{NaCl}$ vs $\mathrm{Sb}$ to sucrose, Friedman ANOVA; $\left.\chi^{2}=7.36 ; p<0.01\right)$ (Fig. $4 A$ ) (Ns to $\mathrm{NaCl}$ vs Ss to sucrose, $\chi^{2}=8.42 ; p<0.01$ ) (Fig. $4 B)$. Post hoc $t$ tests revealed significant differences between $\mathrm{NaCl}$-best and sucrose-best cells in responses recorded 10, 15, 20, 25 , and $30 \mathrm{~min}$ after the onset of lipid infusion $(p<0.01$, at 10 min; $p<0.05$, at 15-30 min) (Fig. 4A) and between NaCl-specific and sucrose-specific cells in samples taken 5, 10, 15, 20, and 25 min after lipid $(p<0.05 ; n=5 ; p<0.01 ; n=8$; $p<0.05 ; n=$ $8 ; 5,10-15$, and 20-25, respectively) (Fig. $4 B$ ).

Although all effects were reversible within the time frame of a normal meal, the duration of the suppression of salt responses in $\mathrm{NaCl}$-best cells was shorter than for sucrose responses in sucrosebest neurons. The inhibition of $\mathrm{NaCl}$-best cells to an $\mathrm{NaCl}$ stimulus recovered by $20 \mathrm{~min}$ after the onset of lipid infusion, whereas the sucrose responses of sucrose-best units required 35 min to return to their basal levels (Fig. 4A). The differences in the duration of the inhibitory effects was even greater for the neurons that responded specifically to either sucrose or $\mathrm{NaCl}$ (Fig. 4B). In fact, the $\mathrm{NaCl}$-specific cells failed to exhibit a significant decrease in response magnitude to sapid $\mathrm{NaCl}$ during duodenal lipid infusions. In contrast, the sucrose-specific units displayed a substantial decrease in response magnitude to sapid sucrose that did not recover for $30 \mathrm{~min}$.

\section{Hierarchial cluster analysis}

The results of a hierarchical cluster analysis derived from Pearson's product-moment correlations using the average linkage method appear in Figure 5. The unit numbers and their response characteristics are listed on the left. In the dendrograms, the level at which two neurons, or two clusters of neurons, join indicates their shared correlation coefficient. Thus, a linkage distance (1 Pearson's $r$ ) of 0.0 means an identical response profile, i.e., Pearson's correlation coefficient of 1.00 .

Before the duodenal inf usion, with one exception (unit 5, CSx), the four clusters with the greatest linkage distances, and consequently, the lowest shared correlation coefficients $(r<0.1)$ are coextensive with the four best-stimulus categories (Fig. $5 A$ ). With somewhat less fidelity, the second and third order clusters also reflect the best-stimulus categories, i.e., four of five sucrose-best cells that responded second best to citric acid make up a subcluster with one acid-best sucrose neuron (units 5, 24, 28, 29, and 8). After the lipid infusions (Fig. $5 B$ ), the first order clusters remained primarily defined by best-stimulus category, and the shared correlation coefficients of the first five largest clusters 


\section{Lipid Infusion}
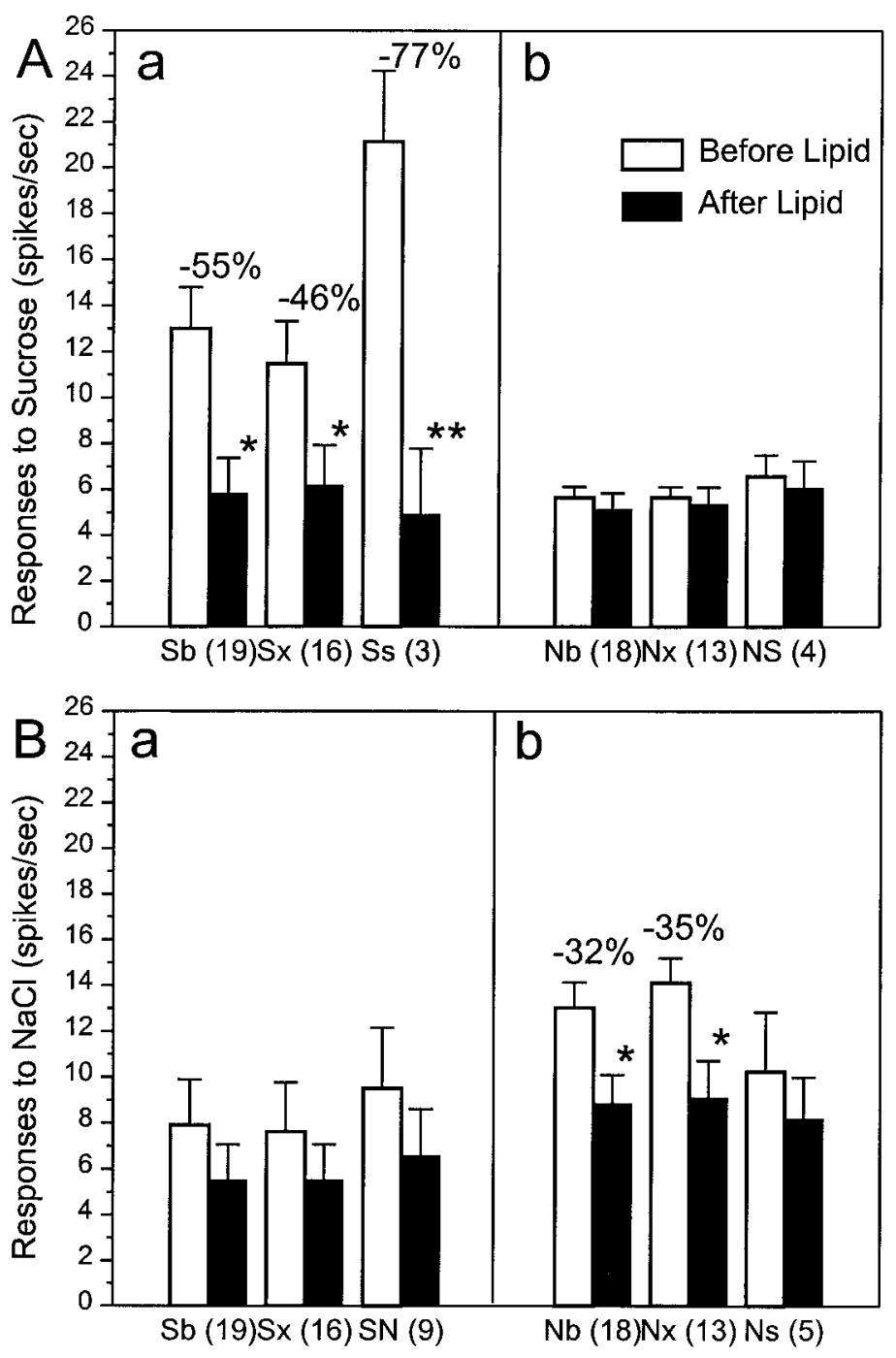

Saline Infusion
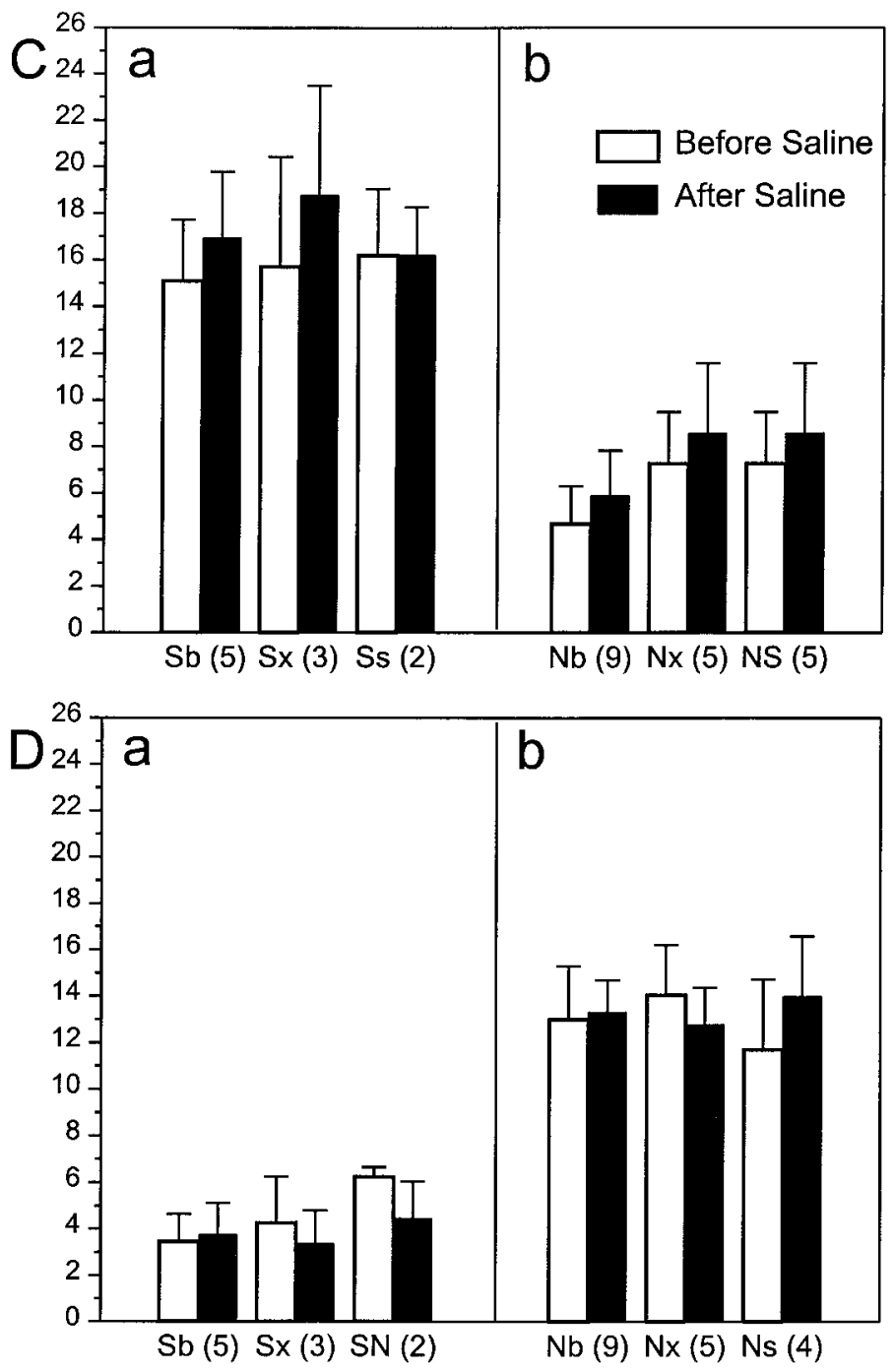

Figure 3. Effect of intraduodenal lipid $(A, B)$ and saline $(C, D)$ on the mean response magnitudes within best-stimulus categories of 59 PBN taste neurons. Top $(A, C)$, Responses to sucrose; bottom $(\mathrm{B}, \mathrm{D})$, responses to $\mathrm{NaCl}$. $\mathrm{Sb}$, All sucrose-best cells; $S x$, sucrose-best cells that also responded significantly to at least one other stimulus; $S s$, sucrose cells that failed to respond to any other stimuli; $S N$, sucrose-best cells that responded second best to $\mathrm{NaCl} ; \mathrm{Nb}$, all NaCl-best; $N x$, NaCl-best cells that also responded to at least one other stimulus; $N s, \mathrm{NaCl}$ cells that failed to respond to any other stimuli; $N S$, NaCl-best cells that responded second best to sucrose. Numbers in parentheses, Number of neurons in each category. Note that $S b=S x+$ $S s$ and $N b=N x+N s$. Open bars, Before infusions; filled bars, after infusions. Percent values in $A a$ and $B b$, Average changes of taste responsiveness to lipid infusions; * $p<0.05 ; * p<0.01$.

changed little compared with those before the lipid (Qb, 0.98 vs 0.99 ; $\mathrm{Cb}, 0.73$ vs 0.78 ; Sb, 0.61 without the SQ units 26 and 36 vs 0.68 for $\mathrm{Sb} 1$ or 0.63 for $\mathrm{Sb} 2$; $\mathrm{Nb}, 0.6$ vs 0.58 , before and after lipid, respectively).

The major change in the dendrograms is that, after lipid infusions, the cluster containing the sucrose-best neurons split into two equal subclusters (Sb1 and Sb2 with 12 neurons in each). Further analysis of the $\mathrm{Sb} 2$ cluster revealed that these cells have lower response rates to their best-stimuli compared with sucroseor $\mathrm{NaCl}$ - best cells in the $\mathrm{Sb} 1$ or $\mathrm{Nb}$ clusters, respectively (mean responses, 3.9 vs $8.05 \mathrm{~Hz}$ for Sb cells in Sb2 and Sb1, respectively; $6.94 \mathrm{vs} 9.61 \mathrm{~Hz}$ for $\mathrm{Nb}$ cells in $\mathrm{Sb} 2$ and $\mathrm{Nb}$, respectively). In fact, after lipid infusions, the suppression of the sucrose responses in the $\mathrm{Sb} 2$ sucrose-best cells was significantly greater than that of the nonspecific sucrose-best cells in the Sb1 cluster (62.5 vs $44.2 \%$; $\chi^{2}$
$=4.5 ; p<0.05)$. The import of the cluster analysis is to demonstrate that, aside from sucrose-best neurons, the response relationships between the neurons did not alter substantially as a function of the intraduodenal infusions.

\section{Summary of the results}

Although intraduodenal infusions of lipid did not change the basic characteristics of PBN taste neurons, overall responsiveness decreased. The magnitude of the reductions in response differed across and within the best-stimulus categories. Specifically, the most pronounced suppression occurred when sucrose-best neurons were tested with sapid sucrose, and this effect was largest for the sucrose-specific cells. Nonspecific NaCl-best neurons also responded less to their best stimulus (i.e., to $\mathrm{NaCl}$ ) after lipid infusions, but the NaCl-specific cells did not. Furthermore, in- 

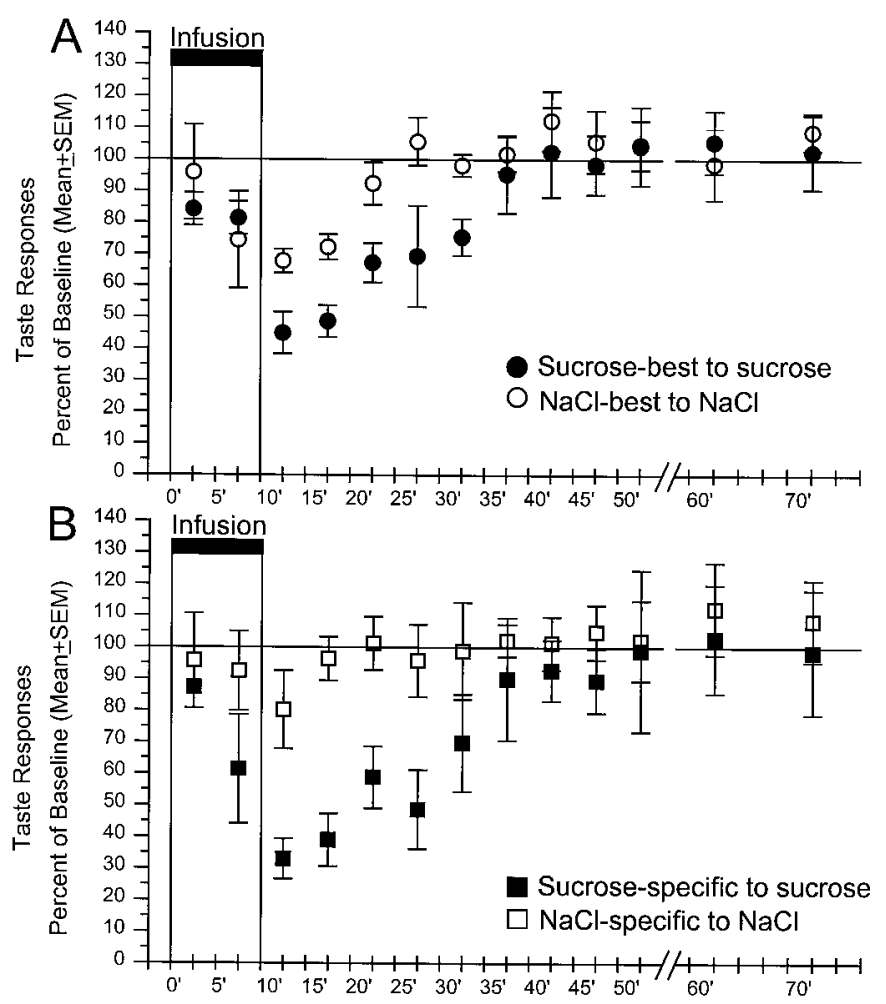

Figure 4. Time course of the intraduodenal lipid effect on the mean response magnitudes of NaCl-best and sucrose-best cells $(A)$ and sucrosespecific and $\mathrm{NaCl}$-specific cells $(B)$ in response to their best stimulus. Mean \pm SEM responses are expressed as a percentage of the mean responses before lipid inf usions (e.g., "baseline" at 100\%). Abscissa, Time in minutes after the onset of the lipid infusion. Stimuli were applied every $5 \mathrm{~min}$. After $50 \mathrm{~min}$, data from every other trial are displayed. The number of cells tested at each time point varied, because not all cells remained isolated for the same period. The time course of the lipid effect was similar, even when the data came only from cells that were tested over the entire period. $n$ values for the first test after the offset of the lipid infusion (10-15 $\mathrm{min})$ were as follows: sucrose-best (open circles), 19; NaCl-best (filled circles), 18; sucrose-specific (filled squares), 3; NaClspecific (open squares), 5 .

traduodenal lipid infusions failed to decrease the responses of nonspecific sucrose-best cells to $\mathrm{NaCl}$ or of nonspecific $\mathrm{NaCl}$-best neurons to sucrose. No significant changes were observed in response to citric acid or $\mathrm{QHCl}$ for any cells in the sample, nor did citric acid-best or QHCl-best neurons alter their responses to sucrose or $\mathrm{NaCl}$. Although all effects appeared with short latency and were reversible within the time frame of a meal, significant differences did occur in the rate of recovery of the gustatory responses. The suppressive effect of lipid on responses to sucrose was longer than for responses to $\mathrm{NaCl}$. In controls, no changes were observed in taste responses as a function of duodenal saline infusion.

\section{DISCUSSION}

The major observation of this study is that intestinal lipid infusions have an effect on central gustatory coding that is both neuron- and stimulus-specific. The results are consistent with previous behavioral findings that intraduodenal lipid infusions suppress sham feeding (see introductory remarks). Both the behavioral and electrophysiological consequences appear to begin within a few minutes (5-10 min), and both are reversible within a time frame of a meal (30-40 min). This latency is significantly shorter than that for absorption after duodenal infusions (Clark et al., 1973; Holt and Bennett-Clark, 1975; Greenberg et al., 1995) and, thus, indicates a preabsorptive site of action (for review, see Greenberg and Smith, 1996). Furthermore, the changes in PBN taste responsiveness involved the sucrose- and $\mathrm{NaCl}$-best neurons differentially and were not seen in citric acid- and QHCl-best cells. The magnitude of the changes, as well as the differential contribution of specific taste cells, suggests that intestinal fat has rapid feedback effects predominantly on tastes that signal nutritional value.

This nutritional specificity concept is consonant with data from orbitofrontal cortex neurons that respond to specific flavors, such as black current juice and glucose, and lose their response only to the stimulus on which the monkey has been satiated (Rolls et al., 1989). Similar, although less specific, effects also have been noted in multiunit gustatory activity recorded from the nucleus of the solitary tract (NST) in anesthetized rats (Giza et al., 1992). Unlike the current effects, which appear to begin preabsorptively, the NST experiments used intravenous nutrient inf usions, and, in monkeys, the effects occurred with a time course that did not exclude postabsorptive mechanisms. Despite the differences among the experiments, the major effect was similar; nutrients in the body inhibited central taste responses differentially as a function of the nutrient relevance of the sapid stimulus.

In the present experiment, however, the mechanism of this differential effect may arise more from the facilitatory effects of the deprivation state than from differential inhibition imposed by the fat infusions. The rats in our paradigm were somewhat food-deprived but not salt-deprived. This may have contributed to the observed difference in the magnitude and duration of the response decrement to sapid sucrose and $\mathrm{NaCl}$. The largest effect, the $77 \%$ reduction in the response exhibited by sucrose-specific neurons to oral sucrose, resulted more from the greater magnitude of their preinfusion responses, because the absolute level of the postinfusion responses did not differ between the sucrosespecific and the other sucrose-best neurons. In contrast, before the inf usion, the $\mathrm{NaCl}$-specific cells actually displayed somewhat smaller responses to oral $\mathrm{NaCl}$ compared with the other $\mathrm{NaCl}$ best units. Because of that lower preinfusion responsiveness, intraduodenal lipid failed to reduce the responses of these specific cells, although the postinfusion NaCl-responsiveness of entire sample of NaCl-best neurons did decrease. In other words, the effect of lipid in the gut may be relatively nonspecific, in that responses to both sucrose and $\mathrm{NaCl}$ decrease to between five and eight spikes/sec. Nevertheless, by reducing all gustatory responses to the same low level, this effect could contribute to the inhibition of feeding behavior by eliminating those responses that had been selectively facilitated by the need state.

The first interpretation assigns the specificity of the inhibitory response to the gut infusion with or without influence from need state. The second interpretation assigns specificity to the need state, which facilitates neural responses to some sapid stimuli and not others. The inhibition from the gut infusion can be more general. The two interpretations need not be mutually exclusive, nor can the present data distinguish between them.

The only other need state that has been tested during gustatory stimulation is sodium appetite. During dietary sodium deficiency, inhibition of responses to sapid stimuli has been reported at three levels of the gustatory system: the chorda tympani, the NST, and the PBN (Contreras and Frank, 1979; Jacobs et al., 1988; Nakamura and Norgren, 1995; Shimura et al., 1997a). Only one of these reports involved awake behaving animals, and the recording 

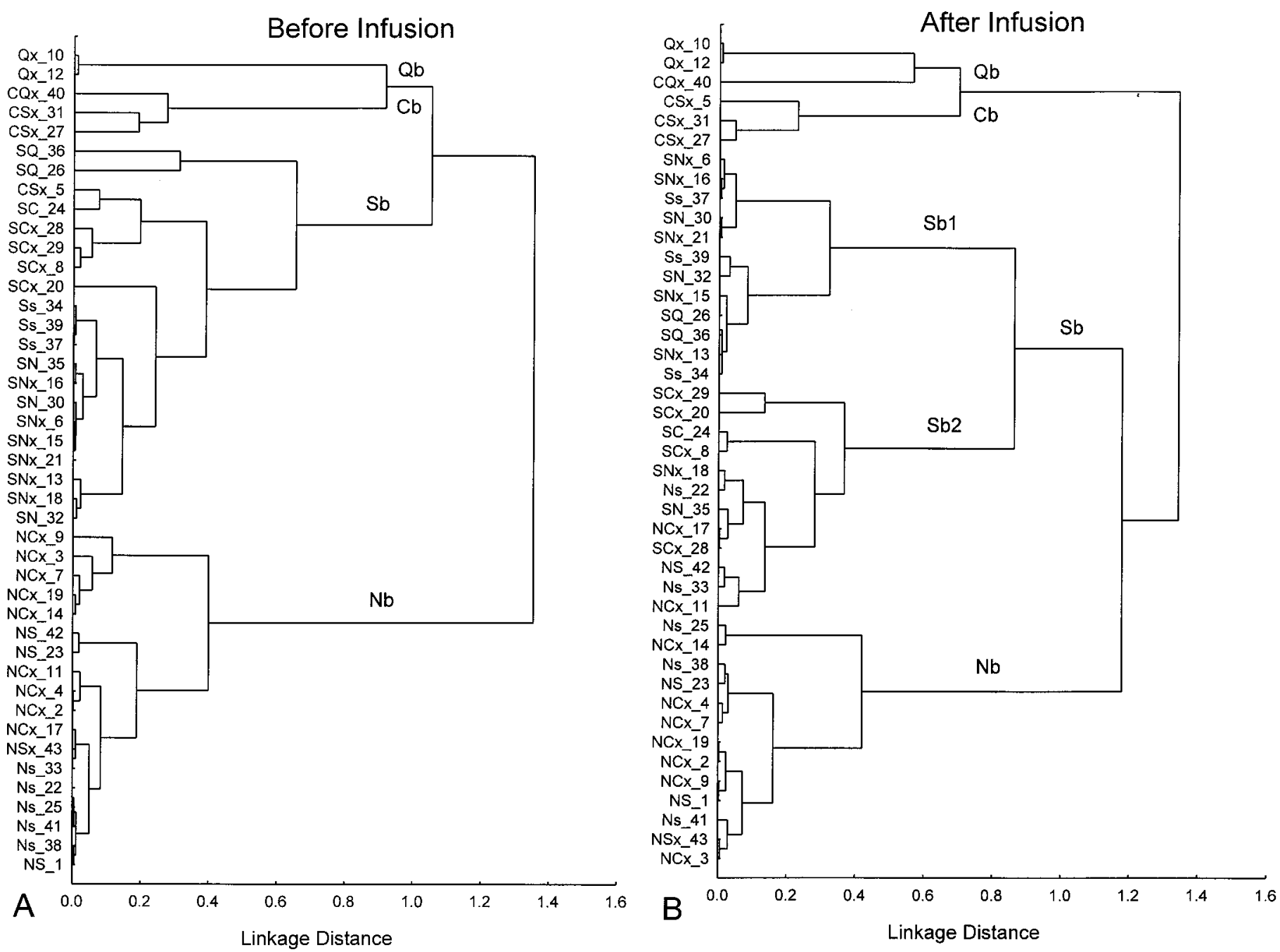

Figure 5. Dendrograms of $43 \mathrm{PBN}$ taste neurons recorded before $(A)$ and after $(B)$ lipid inf usions resulting from a hierarchical cluster analysis using Pearson's product-moment correlation coefficients and the average linkage method. Left, The number of each neuron and response category. Index $x$ means additional, second or third order, taste responses. Abscissa, Linkage distance $(1-$ Pearson's $r)$ between neurons or clusters. For further explanation, see Results.

was in the NST (Nakamura and Norgren, 1995). In all cases, the inhibition resulted from the induction of the need state, not from its relief. One other experiment in the NST reported enhanced responses during sodium deficiency (Tamura and Norgren, 1997). In this case, the appetite was induced rapidly using a diuretic, furosemide. This treatment aroused the animals sufficiently that they required light anesthesia for the recording to proceed. In any event, none of the experiments with sodium appetite involved satiation of the need state, and only one involved the PBN and that was in anesthetized preparations (Shimura et al., 1997a). An experiment parallel to the present one that imposes a sodium rather than a caloric deficit and that uses duodenal $\mathrm{NaCl}$ infusions rather than fat is required for a direct comparison of the effects of the two motivational systems on gustatory afferent coding.

Discomfort or illness also can depress food intake and, in the process, produce conditioned taste aversion (CTA) (Garcia et al., 1974), which may alter taste coding (Chang and Scott, 1984; Shimura et al., 1997b). In fact, certain lipids, e.g., oleic acid, can damage the intestinal mucosa and produce a strong CTA to sucrose (Ramirez et al., 1997). In contrast, Intralipid failed to cause signs of discomfort or a CTA (Friedman et al., 1996; Greenberg and Smith, 1996), and, when infused into the duodenum, its satiating effect was indistinguishable from that typically seen after normal ingestion (Greenberg et al., 1990). Although our infusions were more rapid than what is used typically, if the lipid was inducing a CTA, our rats would have ingested less sucrose during training or rejected it during the recording session, which they did not. Furthermore, a CTA to sucrose also would have altered the behavior and neural activity in controls, half of which were trained with intraduodenal lipid, but whose neural responses were recorded during saline infusion. All this suggests that the observed effects were specific to lipid and not the result of a CTA nor of the mechanical or osmotic consequences of the volume injected.

One concomitant of satiety is a change in the hedonic valence of the consummatory stimulus. Such a change is reasonably easy to assess in humans (Rolls et al., 1982; Johnson and Vickers, 1993; Simon et al., 1993; Halmi, 1995) and has been inferred from the behavior of animals (Antin et al., 1977; Foster et al., 1996, 1998). The neural basis for such changes animates research into motivational effects on sensory coding in general, and on gustatory 
afferent activity in particular, because some tastes appear to have inherent hedonic characteristics. The neurons that responded most specifically to sucrose were the most affected by the intraduodenal lipid infusion. Such specificity could lend credence to the idea that the most narrowly tuned gustatory cells are more sensitive to the need state of the animal and thus provide a disproportionate share of the hedonic information about sapid stimuli.

\section{REFERENCES}

Antin J, Gibbs J, Smith GP (1977) Intestinal satiety requires pregastric food stimulation. Physiol Behav 18:421-425.

Chang FC, Scott TR (1984) Conditioned taste aversions modify neural responses in the rat nucleus tractus solitarius. J Neurosci 4:1850-1862.

Clark SB, Lawergren B, Martin JV (1973) Regional intestinal absorptive capacities for triolein: an alternative to markers. Am J Physiol 225:574-585.

Contreras RJ, Frank M (1979) Sodium deprivation alters neural responses to gustatory stimuli. J Gen Physiol 73:569-594.

Foster LA, Nakamura K, Greenberg D, Norgren R (1996) Intestinal fat differentially suppresses sham feeding of different gustatory stimuli. Am J Physiol 270:R1122-R1125.

Foster LA, Boeshore K, Norgren R (1998) Intestinal fat suppressed intake of fat longer than intestinal sucrose. Physiol Behav 64:451-455.

Friedman MI, Ramirez I, Tordoff MG (1996) Gastric emptying of ingested fat emulsion in rats: implications for studies of fat-induced satiety. Am J Physiol 270:R688-R692.

Garcia J, Hankins WG, Rusiniak KW (1974) Behavioral regulation of the milieu interne in man and rat. Science 185:824-831.

Giza BK, Scott TR, Vanderweele DA (1992) Administration of satiety factors and gustatory responsiveness in the nucleus tractus solitarius of the rat. Brain Res Bull 28:637-639.

Greenberg D, Smith GP (1996) The controls of fat intake. Psychosom Med 58:559-569.

Greenberg D, Smith GP, Gibbs J (1990) Intraduodenal infusions of fats elicit satiety in sham-feeding rats. Am J Physiol 259:R110-R118.

Greenberg D, Kava RA, Lewis DR, Greenwood MR, Smith GP (1995) Time course for entry of intestinally infused lipids into blood of rats. Am J Physiol 269:R432-R436.

Gregory PC, Rayner DV (1987) The influence of gastrointestinal infusion of fats on regulation of food intake in pigs. J Physiol (Lond) 385:471-481.

Grill HJ, Norgren R (1978a) The taste reactivity test. I. Mimetic responses to gustatory stimuli in neurologically normal rats. Brain Res 143:263-279.

Grill HJ, Norgren R (1978b) The taste reactivity test. II. Mimetic responses to gustatory stimuli in chronic thalamic and chronic decerebrate rats. Brain Res 143:281-297.

Hajnal A, Takenouchi K, Norgren R (1998) Parabrachial gustatory neural responses to intraduodenal infusion of lipid in awake rats. Soc Neurosci Abstr 24:1887.

Halmi KA (1995) Basic biological overview of eating disorders. In: Psychopharmacology: the 4th generation of progress (Bloom FE, Kupfer DJ, eds), pp 1610-1616. New York: Raven.

Holt PR, Bennett-Clark S (1975) Fat absorption. In: Function of the stomach and intestine (Friedman MHF, ed), pp 285-299. Baltimore: University Press.

Jacobs KM, Mark GP, Scott TR (1988) Taste responses in the nucleus tractus solitarius of sodium-deprived rats. J Physiol (Lond) 406:393-410.

Johnson J, Vickers Z (1993) Effects of flavor and macronutrient composition of food servings on liking, hunger and subsequent intake. Appetite 21:25-39.
Liebling DS, Eisner JD, Gibbs J, Smith GP (1975) Intestinal satiety in rats. J Comp Physiol Psychol 89:955-965.

Nakamura K, Norgren R (1995) Sodium-deficient diet reduces gustatory activity in the nucleus of the solitary tract of behaving rats. Am J Physiol 269:R647-R661.

Nishijo H, Norgren R (1990) Responses from parabrachial gustatory neurons in behaving rats. J Neurophysiol 63:707-724.

Nishijo H, Norgren R (1991) Parabrachial gustatory neural activity during licking by rats. J Neurophysiol 66:974-985.

Nishijo H, Norgren R (1997) Parabrachial neural coding of taste stimuli in awake rats. J Neurophysiol 78:2254-2268.

Norgren R (1974) Gustatory afferents to ventral forebrain. Brain Res 81:285-295.

Norgren R (1976) Taste pathways to hypothalamus and amygdala. J Comp Neurol 116:12-30.

Norgren R (1990) The gustatory system. In: The human nervous system (Paxinos G, ed), pp 845-861. San Diego: Academic.

Norgren R (1995) Gustatory system. In: The rat nervous system. (Paxinos G, ed), pp 751-771. New York: Academic.

Norgren R, Pfaffmann C (1975) The pontine taste area in the rat. Brain Res 91:99-117.

Novin D, Sanderson J, Gonzalez M (1979) Feeding after nutrient infusions: effects of hypothalamic lesions and vagotomy. Physiol Behav 22:107-113.

Phillips MI, Norgren R (1970) A rapid method for permanent implantation of an intraoral fistula in rats. Behav Res Methods Instrum 2:124.

Ramirez I, Tordoff MG, Friedman MI (1997) Satiety from fat? Adverse effects of intestinal infusion of sodium oleate. Am J Physiol 273:R1779-R1785.

Reidelberger RD, Kalogeris TJ, Leung PM, Mendel VE (1983) Postgastric satiety in the sham-feeding rat. Am J Physiol 244:R872-R881.

Rolls BJ, Rowe EA, Rolls ET (1982) How sensory properties of foods affect human feeding behavior. Physiol Behav 29:409-417.

Rolls ET, Sienkiewicz ZJ, Yaxley S (1989) Hunger modulates the responses to gustatory stimuli of single neurons in the caudolateral orbitofrontal cortex of the macaque monkey. Eur $\mathrm{J}$ Neurosci $1: 53-60$.

Shimura T, Komori M, Yamamoto T (1997a) Acute sodium deficiency reduces gustatory responsiveness to $\mathrm{NaCl}$ in the parabrachial nucleus of rats. Neurosci Lett 236:33-36.

Shimura T, Tanaka H, Yamamoto T (1997b) Salient responsiveness of parabrachial neurons to the conditioned stimulus after the acquisition of taste aversion learning in rats. Neuroscience 81:239-247.

Simon Y, Bellisle F, Monneuse MO, Samuel-Lajeunesse B, Drewnowski A (1993) Taste responsiveness in anorexia nervosa. Br J Psychiatry 162:244-246.

Smith DV, Travers JB (1979) A metric for the breadth of gustatory neurons. Chem Senses 4:215-229.

Smith GP (1996) The direct and indirect controls of meal size. Neurosci Biobehav Rev 20:41-46.

Tamura R, Norgren R (1997) The effect of repeated sodium depletion on gustatory neural responses in the nucleus of the solitary tract of the rat. Am J Physiol 273:R1381-R1391.

Walls EK, Phillips RJ, Wang FB, Holst MC, Powley TL (1995) Suppression of meal size by intestinal nutrients is eliminated by celiac vagal deafferentation. Am J Physiol 269:R1410-R1419.

Warwick ZS (1996) Probing the causes of high-fat diet hyperphagia: a mechanistic and behavioral dissection. Neurosci Biobehav Rev 20:155-161.

Warwick ZS, Schiffman SS (1992) Role of dietary fat in calorie intake and weight gain. Neurosci Biobehav Rev 16:585-596.

Welch IM, Sepple CP, Read NW (1988) Comparisons of the effects on satiety and eating behaviour of infusion of lipid into the different regions of the small intestine. Gut 29:306-311. 